\title{
OS FUNDAMENTOS ONTOLÓGICOS DA DIDÁTICA: A MEDIAÇÃO COMPREENDIDA A PARTIR DA ONTOLOGIA DO SER SOCIAL
}

\author{
FUNDAMENTOS DE LA ONTOLÓGICA ENSEÑANZA: LA MEDIACIÓN \\ ENTENDERSE A PARTIR DE SER ONTOLOGÍA SOCIAL
}

\author{
THE ONTOLOGICAL FOUNDATIONS OF DIDACTICS: THE MEDIATION \\ UNDERSTOOD FROM THE ONTOLOGY OF THE SOCIAL BEING
}

José Luís Vieira de ALMEIDA ${ }^{1}$

\begin{abstract}
RESUMO: Este texto enfoca a mediação na perspectiva da Ontologia do Ser Social e também como categoria central nas atividades educativas. Compreendida dessa maneira, a mediação se torna fundamental para a Didática. A mediação e a Ontologia do Ser Social devem fundamentar a Didática porque ela sempre estabelece uma relação entre o imediato e o mediato - mediação. A mediação é ontológica por ser uma possibilidade exclusiva do ser humano, mas o caráter ontológico da didática não se limita à mediação. Ele também se expressa na preocupação fundamental da didática que está voltada para a compreensão dos processos que envolvem o ensino e, dessa forma, permitem que se aprenda. Cabe lembrar que ensinar e aprender também são possibilidades restritas ao ser humano, o que reforça o cunho ontológico da didática. Além disso, no âmbito escolar, o ensino e a aprendizagem exprimem uma tensão entre um professor que é único e os seus alunos que são vários, dois, dez, quarenta... Pensando-se, por exemplo, numa aula expositiva: a fala do professor é única, mas e a compreensão dos alunos? Desse modo, não basta afirmar que a didática é ontológica, faz-se necessário dizer que ela deve pautar-se na Ontologia do Ser Social. Para discutir "os fundamentos ontológicos da didática", optou-se pela apresentação de três tópicos. No primeiro, discute-se a mediação; no segundo, oferecem-se pistas à pergunta formulada no parágrafo anterior; e no terceiro, discute-se a didática. Na conclusão, procura-se estabelecer uma síntese dos tópicos desenvolvidos, evidenciando-se o cunho ontológico da Didática expresso na mediação que se estabelece entre o professor e o estudante.
\end{abstract}

PALAVRAS-CHAVE: Mediação. Didática. Fundamentos.

RESUMEN: Este texto se centra en la mediación en vista de la Ontología del Ser Social y como una categoría central en las actividades educativas. Entendido de esta manera, se convierte en esencial para la mediación didáctica. La mediación y la Ontología del Ser Social deben basar didáctica, ya que siempre se establece una relación entre el inmediato y mediato - mediación. La mediación es ontológica, porque

${ }^{1}$ Universidade Estadual Paulista "Júlio de Mesquita Filho" - UNESP, Programa de Pós-Graduação em Educação Escolar - Câmpus de Araraquara Departamento de Educação do Câmpus de São José do Rio Preto..joseluisv@terra.com.br 
es una posibilidad única del ser humano, pero el carácter ontológico de la enseñanza no se limita a la mediación. También expresó la preocupación fundamental de la enseñanza que se concentra en la comprensión de los procesos que implican la enseñanza y por lo tanto le permiten aprender. Hay que recordar que la enseñanza y el aprendizaje son también posibilidades restringidas a los seres humanos, lo que refuerza la naturaleza ontológica de la enseñanza. Por otra parte, en las escuelas, la enseñanza y el aprendizaje expresan una tensión entre un maestro que es única y sus estudiantes son muchas, dos, diez, cuarenta ... pensando, por ejemplo, en una conferencia: ¿el habla maestro es único, pero y la comprensión de los estudiantes? Por lo tanto, no sólo decir que la enseñanza es ontológica, es necesario decir, que debe estar basada en la Ontología del Ser Social. Para discutir "los fundamentos ontológicos de la enseñanza", se optó por la presentación de tres temas. En un primer momento, se discute la mediación; la segunda, para ofrecer pistas sobre la cuestión planteada en el párrafo anterior; y en tercer lugar, se discute la didáctica. En conclusión, se pretende establecer una visión general de los temas desarrollados, lo que demuestra la naturaleza ontológica de la didáctica se expresa en la mediación que se establece entre el maestro y el estudiante.

PALABRAS CLAVE: Mediación. Didáctica. Fundamentos.

ABSTRACT: This text focuses on mediation in the perspective of the Ontology of Social Being and also as a central category in educational activities. Understood in this way, mediation becomes central to Didactics. The mediation and the Ontology of the Social Being must support Didactics because it always establishes a relation between the immediate and the mediate. Mediation is ontological because it is an exclusive possibility of the human being, but the ontological character of didactics is not limited to mediation. It is also expressed in the fundamental concern of didactics that is focused on understanding the processes that involve teaching and, in this way, allow learning. It should be remembered that teaching and learning are also possibilities restricted to the human being, which reinforces the ontological nature of didactics. In addition, in the school context, teaching and learning express a tension between a teacher who is unique and his / her students who are several, two, ten, and forty ... Thinking, for example, in an expositive class: speech of the teacher is unique, but what about the students' understanding? Thus, it is not enough to say that the didactic is ontological, it is necessary to say that it must be based on the Ontology of the Social Being. To discuss "the ontological foundations of didactics", we chose to present three topics. In the first, mediation is discussed; In the second, clues are given to the question posed in the previous paragraph; And in the third, didactics is discussed. In the conclusion, we try to establish a synthesis of the topics developed, evidencing the ontological nature of Didactics expressed in the mediation that is established between the teacher and the student.

KEYWORDS: Mediation. Didactics. Fundamentals.

\section{Introdução}


Este texto enfoca a mediação na perspectiva da ontologia do ser social e também como categoria central nas atividades educativas. Compreendida dessa maneira, a mediação se torna fundamental para a Didática.

A Didática é um campo do conhecimento fundado na mediação e sempre o foi, embora seja anterior ao desenvolvimento da mediação como categoria filosófica. A Didática também é e sempre foi ontológica, no sentido da ontologia do ser social, apesar de ser anterior às formulações de G.W.F. Hegel $(\underline{1770}$ - $\underline{1831})$ e K. Marx (1818 1883), que são os fundadores daquela ontologia. Apontar o caráter precursor da Didática não implica negar a história nem afirmar que tal caráter esteve ou está explícito. Ao contrário, pretende-se mostrar que, a despeito de serem próprias da Didática, a mediação e a ontologia do ser social estão ausentes das discussões e da maior parte dos estudos relativos a esse campo do conhecimento.

A mediação e a ontologia do ser social são próprias da Didática porque ela sempre estabelece uma relação entre o imediato e o mediato - mediação. A mediação é ontológica por ser uma possibilidade exclusiva do ser humano, mas o caráter ontológico da Didática não se limita à mediação. Ele também se expressa na preocupação fundamental da Didática que está voltada para a compreensão dos processos que envolvem o ensino e, dessa forma, permitem que se aprenda. Cabe lembrar que ensinar e aprender também são possibilidades restritas ao ser humano, o que reforça o cunho ontológico da Didática. Além disso, no âmbito escolar, o ensino e a aprendizagem exprimem uma tensão entre um professor que é único e os seus alunos que são vários, dois, dez, quarenta... Pensando-se, por exemplo, numa aula expositiva: a fala do professor é única, mas e a compreensão dos alunos? Desse modo, não basta afirmar que a Didática é ontológica, faz-se necessário dizer que ela deve pautar-se na ontologia do ser social.

Para discutir os fundamentos ontológicos da Didática, optou-se pela apresentação de três tópicos. No primeiro, discute-se a mediação; no segundo, oferecem-se pistas à pergunta formulada no parágrafo anterior; e no terceiro, discute-se a Didática. Na conclusão, procura-se estabelecer uma síntese dos tópicos desenvolvidos.

\section{A mediação}


O uso do vocábulo mediação tem sido frequente entre os pesquisadores do campo da educação no Brasil, e esta frequência é diretamente proporcional à imprecisão dos sentidos que ele assume. A palavra mediação pode se referir ao termo médio de uma relação entre elementos equidistantes, ou à ligação entre dois termos distintos, ou ainda à passagem de um termo a outro. Ela pode também dizer respeito à harmonização de conflitos entre interesses opostos (antagônicos ou não). Fala-se, por exemplo, no professor como mediador da relação ensino-aprendizagem, ou no caráter mediador presente no (falso) vínculo que se estabelece entre o conhecimento sistematizado pelas ciências naturais e/ou sociais e aquele que o aluno desenvolve no seu cotidiano. Assim, atribui-se à mediação a possibilidade ou o dever de eliminar ou minimizar a diferença entre os termos ensino e aprendizagem ou entre o conhecimento sistemático e a experiência cotidiana, ou ainda entre o professor e os seus alunos. Entendida dessa forma, a mediação tem o sentido de união, de unificação, de igualdade e, sobretudo, é compreendida como resultado, como produto de uma relação entre dois elementos considerados antagônicos que, por meio dela, podem ser homogeneizados.

Quando se compreende a mediação como um produto, a necessária relação entre dois termos se reduz a sua soma, o que resulta na anulação mútua de ambos, levando-os ao equilíbrio. Essa ideia, que é difundida no âmbito da educação, concebe a mediação como o resultado da aproximação entre dois termos que, embora distintos no início da relação, quando totalmente separados, tendem a igualar-se à medida que se aproximam um do outro. Este modo de compreender a mediação, apesar de, aparentemente, contribuir para o entendimento do processo educativo, está distante daquele que se desenvolve na filosofia Tanto de G.W.F. Hegel quanto de K. Marx.

O autor desse texto considera que é sempre oportuno reafirmar que a mediação é uma categoria filosófica que alcança seu pleno desenvolvimento em Hegel, logo, ela é dialética e não pode ser entendida fora da perspectiva deste método de análise. Cabe então advertir que a mediação não pode ser considerada um produto, pois esta noção não tem lugar na dialética; ela aceita apenas a ideia de processo, que se pauta na força e no movimento.

O movimento, além de ser contínuo, não apresenta limites, começo ou fim, o que de modo algum o faz desordenado: ele se organiza a partir da negação recíproca estabelecida entre os elementos envolvidos na relação. Esse negar mútuo não permite que a mediação, quando entendida como uma relação dialética, compreenda ideias que tenham por base a igualdade, a homogeneidade, a aproximação ou o equilíbrio; ao 
contrário, ela tem por referência a diferença, a heterogeneidade, a repulsão e o desequilíbrio. O movimento e a negatividade da mediação só são dotados de sentido na perspectiva da superação, outra categoria da lógica dialética. Assim, o movimento que não admita a negatividade não pode superar a contradição inerente a ele.

Na lógica dialética, o movimento, a contradição e a sua superação, constituintes da mediação, não podem ser entendidos de modo linear, o que os faria cumulativos. Esses três elementos devem ser concebidos numa perspectiva circular - espiral. Assim, no círculo aberto, o começo e o fím coincidem, mas esta coincidência não os torna idênticos, pois ambos se negam mutuamente. Dessa forma, todo começo prenuncia o fim por meio da sua negação e todo fim, também pela via da negação, remete ao seu começo e a um novo começo: “o círculo é um círculo de círculos" (HEGEL, apud LUKÁCS, 1979a, p 70 -71). No círculo, todo fim implica retorno ao começo, engendrando o começo de um novo membro. A negação recíproca entre o começo e o fim permite a superação de ambos no novo começo, portanto, se a relação entre estes dois termos não fosse pautada na negatividade, o círculo permaneceria fechado, e o movimento se limitaria à repetição.

Quando se compreende o movimento e a negatividade dialeticamente, a mediação não pode ser pensada como uma soma de vetores que se anulam mutuamente, criando, ao mesmo tempo, um ponto de equilíbrio.

Foi necessário tratar da circularidade e da sua importância nas formulações da dialética de Hegel e de Marx antes de discutir a mediação para demonstrar, também, que não se pode estabelecer uma hierarquia entre os termos passíveis de mediação. Em Hegel, a mediação refere-se à relação entre o imediato e o mediato:

Todo conhecimento real deve passar por três momentos: o do imediato ou do universal abstrato, depois o de sua negação, que é reflexão, mediação e o da totalidade concreta, do universal concreto, isto é, do resultado que conserva e contém nele o momento da negação, da reflexão, da mediação (GARAUDY,1983, p:28).

A mediação é, portanto, uma força negativa que une o imediato ao mediato e, por isso, também os separa e os distingue. Apesar de permitir a passagem de um termo a outro, ela não é apenas uma 'ponte' entre os dois polos, ela é um dos elementos da relação responsável por viabilizá-la. A mediação permite, pela negação, que o imediato seja superado no mediato sem que o primeiro seja anulado ou suprimido pelo segundo, ao contrário, o imediato está presente no mediato e este está presente naquele, então ela 
(a mediação) é a responsável pela reflexão recíproca de um termo no outro. O mediato não supera o imediato, quem o faz é a mediação, assim, a força inerente à superação não se manifesta nos polos da relação, o imediato e o mediato, ela é uma propriedade da mediação.

A mediação não se restringe a uma relação pautada na negação e no reflexo, ela é, sobretudo, o modo pelo qual se dá a superação:

\begin{abstract}
A 'superação' no devir não é aniquilamento, mas metamorfose. O que é destruído é a imediaticidade primitiva, na passagem a uma outra coisa ou a um outro estado, no devir mais simples já se exprime a primeira forma de mediação, da ligação entre os seres aí. A superação é a passagem da presença imediata à mediação que pode tomar as mais diversas formas. Se empregarmos metáforas espaciais ou temporais diríamos que um objeto pode, por exemplo, definir-se pela mediação de outros objetos com os quais está em relação ou ainda, na duração, passagem do ser a seu outro, ou do passado ao presente, não é supressão pura e simples, mas superação que é ao mesmo tempo negação e integração (GARAUDY, 1983, p 121-122).
\end{abstract}

De acordo com Garaudy, a superação do imediato ocorre na mediação; o mediato é, então, o estado que dela decorre. A superação só se viabiliza quando coisas ou estados distintos estabelecem relações entre si, mas elas devem ser de mediação, que é uma relação qualitativa fundada na força e caracterizada pela negatividade e pelo reflexo. Quando se trata da superação, deve-se ter claro que ela sempre se refere a uma contradição. Por isso, se a superação ocorre na mediação, a contradição também se manifesta nela. Assim, não se pode buscá-las nas coisas, mas nas relações de mediação que elas mantêm entre si.

A passagem de uma coisa à outra ou de um estado a outro por meio da superação não suprime a coisa ou o estado superados, ao contrário, integra-os àqueles que os superaram. Eles não são suprimidos porque também contribuem no processo de superação. A mediação na qual se dá a superação, não é unilateral nem excludente, busca a totalidade e, assim, combate a unilateralidade da parte sem excluí-la do todo e, ao mesmo tempo, sem diluí-la nele.

Até aqui, a mediação foi discutida, como superação do imediato no mediato. O acento nesta lógica permite o entendimento das categorias do método dialético que fundamentam a mediação, a saber: o movimento e a negatividade, a circularidade e a totalidade, a contradição e a superação. Cabe agora discutir qual é a sua dinâmica, como ela (a mediação) ocorre. 
A mediação é um atributo exclusivo do ser humano, compreendido aqui como ser social, pois somente o ser humano pode ascender ao plano do mediato e, assim, estabelecer relações de mediação com a natureza e com os outros homens. Os outros animais vivem na natureza, mas não se relacionam com ela, não a compreendem nem a transformam. O seu contato com os outros seres vivos obedece aos seus instintos de sobrevivência. Para Mészáros (1981), a mediação do homem com a natureza e os outros homens se configura como automediação:

\begin{abstract}
A relação entre o homem e a natureza é 'automediadora' num duplo sentido. Primeiro, porque é a natureza que propicia a mediação entre si mesma e o homem; segundo, porque a própria atividade mediadora é apenas um atributo do homem, localizado numa parte específica da natureza. Assim, na atividade produtiva, sob o primeiro desses dois aspectos ontológicos a natureza faz a mediação entre si mesma e a natureza; e, sob o segundo aspecto ontológico - em virtude do fato de ser a atividade produtiva inerentemente social - o homem faz a mediação entre si mesmo e os demais homens (MÉSZÁROS, 1981, p 77-78).
\end{abstract}

A automediação, de acordo com essa formulação, não exclui o homem da natureza, mas o distingue dela. Ele está localizado numa parte específica da natureza. Essa condição permite ao homem interferir nela. Nesse sentido, a natureza se autotransforma, na medida em que o homem, agente da transformação, está inserido nela. É a natureza quem “propicia a mediação entre si mesma e o homem”, em primeiro lugar porque o homem é também natureza e em segundo lugar porque ela oferece as condições para que o ser humano a modifique. Por exemplo, o solo pode ser cultivado, o curso dos rios pode ser alterado e os diamantes podem ser lapidados. Este é o primeiro dos sentidos da automediação destacados por Mészáros (1981); o segundo diz respeito à mediação entre o homem e os outros homens que só se realiza por meio da atividade produtiva que é o modo pelo qual o ser humano transforma a natureza. Como os homens não se separam da natureza, as relações entre eles não podem se desenvolver fora dela.

$\mathrm{Na}$ automediação enfatiza-se o caráter ontológico da mediação e, por isso, para compreendê-la adequadamente, é necessário que se aprofunde o exame da mediação com base na contradição. Para Marx, ela não está presente apenas quando da passagem de um estado a outro nos momentos de ruptura, como ocorre com Hegel, ao contrário, a contradição desenvolve-se no processo normal: 
Por exemplo, é uma contradição que um corpo tenda constantemente para outro e dele se afaste com igual constância. 'A elipse é uma das formas de movimento na qual essa contradição se realiza e, ao mesmo tempo, se resolve'. Nessa concepção [...] a contraditoriedade se apresenta como motor permanente da relação dinâmica entre complexos, entre processos que surgem de tais relações (MARX, apud LUKÁCS, 1979b: 21-22).

A contradição está presente no movimento normal e é a responsável pelo caráter reflexivo dessas relações próprias dele: na relação em que não há contradição, não pode haver reflexo. Como todo reflexo só se estabelece por intermédio da mediação, pode-se afirmar que a contradição manifesta-se na mediação, portanto toda mediação é contraditória, mesmo quando se trata do processo normal, em que não há superação de um estado por outro, como, por exemplo, nas relações que se estabelecem entre o homem e a natureza. A contradição pode ocorrer no movimento normal graças à concepção de momento predominante, desenvolvida por Marx.

No momento predominante, os dois elementos de uma relação reflexiva, contraditórios entre si, podem manifestar-se sem que, necessariamente, um deles seja superado pelo outro. Ambos convivem em desequilíbrio, de tal sorte que um sobrepuja o outro, mas isso não é permanente, se altera, permitindo que o dominado domine a relação. Essa segunda situação deve também se inverter, resultando novamente numa situação semelhante à primeira. Assim, a contradição se "realiza e se resolve". Ela não é excluída ou minimizada, mas se torna permanente, não implicando nem equilíbrio entre os termos, nem superação de um pelo outro. Porém, quando há contradição, há sempre a possibilidade de superação. O momento predominante não dilui a contradição, inversamente, afirma a sua existência, pois tem como fundamento a mediação; é somente por meio dela que se pode admitir a passagem recíproca de um termo a outro da relação, sem que o equilíbrio ou a superação sejam uma decorrência.

\section{Numa aula expositiva a fala do professor é única, mas e a compreensão dos alunos?}

Na discussão de Lukács (1982), a mediação se funda em três categorias: a generalidade, a particularidade e a singularidade. O ser humano estabelece vínculos tanto com a natureza, quanto com a sociedade por meio da relação dialética que se desenvolve entre seu ser singular, que não se assemelha a nenhum outro, e o seu ser geral, que se identifica com os outros seres humanos na vida em sociedade e com a 
espécie, bem como com todos os seres vivos, na natureza. Assim, o homem é, ao mesmo tempo, portador de uma singularidade, que o distingue de todos os outros seres, e de uma generalidade que o torna um ser semelhante a qualquer outro: a relação dialética entre a diferença (singular) e a semelhança (geral) viabiliza a inserção do ser humano na natureza e na sociedade. Por isso, a singularidade e a generalidade, embora sejam estados do ser, devem ser compreendidas no seu movimento de negação recíproca. O singular nega o geral, mas está presente nele e, por outro lado, a generalidade nega a singularidade, porém, só se realiza por meio dela. A negação recíproca entre a singularidade e a generalidade é a particularidade; ela é o movimento que relaciona o singular com o geral.

A particularidade estabelece a mediação entre o singular e o geral; ela é responsável pela relação dos dois termos. Esse movimento torna relativas tanto a generalidade como a singularidade, portanto elas devem ser compreendidas como processos que tendem à generalização e à singularização, respectivamente. Assim, não se pode alcançar a generalidade ou a singularidade, pois cada generalidade alcançada deve ser superada por uma outra que a contém. O mesmo ocorre com a singularidade, ela também deve ser entendida na perspectiva da superação.

O homem singular e o homem geral constituem uma unidade e, ao mesmo tempo, são diversos. Esta unidade na diversidade se efetiva no âmbito do particular, pelo reflexo recíproco dos dois estados do mesmo homem: ele não é só singular ou diverso nem geral ou uno, mas sim singular, geral e particular; diverso e uno.

A particularidade deve ser entendida como um ponto de convergência do geral e do singular, mas ela nunca é soma, nem tampouco um ponto de equilíbrio, ao contrário, ela provoca o desequilíbrio que permite a passagem de um termo a outro; essa passagem implica um processo de superação dos extremos da relação. Da mesma forma, a unidade na diversidade não é a soma do uno e do diverso, ela é a relação de oposição que se estabelece entre eles. Por isso, a particularidade ou a unidade na diversidade, assim como quaisquer outras mediações, não devem ser compreendidas como um ponto médio, embora elas possam ocupar esta posição.

De acordo com Luckács (1982: 213-214), a mediação compreendida numa posição central e, sobretudo, estática, quase sempre se reduz a uma abstração de cunho idealista; ela não ocorre, obrigatoriamente, numa distância equidistante dos termos em relação, ou seja, no centro. Não há um centro fixo; dessa forma, se a mediação ocorrer numa posição aparentemente central, ela não se distingue, não é superior ou inferior a 
qualquer outra e, além do mais, tal posição não é fixa, tende sempre a modificar-se. $\mathrm{O}$ fato de a mediação geralmente não acontecer num ponto central de uma relação explica, em grande parte, a dificuldade apontada por Lukács (1982) quanto ao estabelecimento dos contornos da particularidade na vida cotidiana, pois é pouco provável que ela se situe numa posição central entre a generalidade e a singularidade. Por isso, o particular pode localizar-se ora mais próximo do geral e mais distante do singular, ora mais perto do segundo e, portanto, mais longe do primeiro. A mesma situação ocorre na relação entre o uno e o diverso. Como o posicionamento da mediação não é fixo, ela pode ser confundida com o termo da relação que está mais próximo dela. Dessa forma, a particularidade pode ora se passar por generalidade, ora ser identificada como singularidade. Diante disso, é conveniente lembrar, mais uma vez, a advertência de Lukács (1982) acerca da necessidade de uma visão dialética para que se possa compreender adequadamente o particular diante da vida cotidiana.

A compreensão dialética da particularidade e da unidade na diversidade evita, em primeiro lugar, que se tente identificá-las pela sua posição, supostamente central, equidistante dos termos da relação e, em segundo lugar, não permite que se busque o seu entendimento sem o concurso dos termos da relação (singularidade e generalidade no caso da particularidade e uno e diverso no caso da unidade na diversidade).

Como se pôde verificar, a mediação é fundamental na razão dialética desde Hegel. Esta afirmação também é verdadeira quando se trata das atividades educativas, desde que compreendidas dialeticamente. Porém, é comum entre os professores afirmarse que eles são os mediadores da aprendizagem ou que medeiam na relação ensino aprendizagem. Se coubesse ao docente mediar a relação, ele deveria estar presente nos seus dois polos, ou, ao contrário, adotando-se a ideia de que a mediação é apenas uma 'ponte', o professor não poderia estar presente na relação, permaneceria entre os seus termos para permitir a ligação de ambos. Numa concepção dialética da mediação, essas duas situações não são possíveis, pois o mediar exige dois termos opostos entre si, por exemplo, o ensino oposto à aprendizagem ou o docente oposto ao estudante. Dessa forma, as relações entre o ensino e a aprendizagem e entre o estudante e o professor não podem ser hierárquicas, nem de dominação por um lado ou de subordinação por outro. Elas devem pautar-se pelo esforço de mediação que não é, nem automática nem espontânea. O que ocorre nas relações de mediação é o momento predominante que se verifica quando um polo se sobressai em relação ao outro. Por isso, na relação estudante 
- professor ora predomina a expressão do professor ora a do estudante. Cabe principalmente ao primeiro propiciar a expressão do segundo por meio da mediação.

É preciso assinalar que nessa concepção de mediação o estudante e o docente serão, sempre, opostos entre si, porém não - antagônicos. Por serem opostos, não há harmonia entre eles e, assim, não se pode esperar que desse confronto resulte um estado de equilíbrio. O esforço do professor, que está no plano do mediato, é o de trazer o estudante para esse plano. Por outro lado, o estudante, que quase sempre está confortável no imediato, tenta trazer o professor para este campo. Nesse jogo de forças, no qual ora os conflitos são velados ora são explícitos, é que se dá a mediação.

O entendimento da mediação a partir das categorias singularidade, particularidade e generalidade, bem como tendo por base a unidade, a diversidade e a unidade na diversidade, permite que se compreenda, com clareza, o movimento, a negatividade e a superação no contexto das relações estudante - docente e ensino aprendizagem. O professor e o ensino ocupam o polo da generalidade ou da unidade: um professor, na maior parte das vezes, se relaciona com mais de um estudante e trabalha com os elementos constitutivos de uma área do conhecimento. Por outro lado, o estudante e a aprendizagem se localizam na singularidade ou na diversidade, isto é, não há um aluno que seja igual ao outro, nem mesmo quando eles são irmãos gêmeos. Cada pessoa é única, singular. Desse modo as experiências pessoais são também singulares e diversas, ainda quando elas vivenciam um mesmo episódio, ou desenvolvem atividades comuns como, por exemplo, participam de uma mesma relação educativa. A tensão entre os termos opostos, a generalidade e a singularidade, ou a unidade e a diversidade ocorre por meio da mediação que se expressa tanto na particularidade como na unidade na diversidade. Por isso, nenhuma aula é igual a outra, mesmo quando nelas se aborda o mesmo assunto e se faz uso dos mesmos critérios de seleção e de organização dos tópicos abordados, bem como da mesma metodologia de ensino. Segundo a perspectiva assumida por este texto, a relação educativa só se realiza por meio da expressão da particularidade ou da unidade na diversidade, dessa forma, quando tal expressão não se verifica, não há relação educativa.

\section{A Didática}


A discussão acadêmica sobre a relação ensino-aprendizagem, que se desenvolve no Brasil nos últimos trinta anos, tende a compreender a ambos como termos de uma mesma e única relação. Desta perspectiva, não pode haver ensino quando o aluno não aprende. Nela também se apoia a ideia de que o professor e o aluno tanto ensinam quanto aprendem, ou seja, são indistintos.

O ensino é o objeto de estudo da Didática que, desde os anos setenta, sofre dois processos que a impedem de distinguir o ensino da aprendizagem. Um deles é a 'psicologização da Didática', conforme Warde (1991), e o outro é aquele que reduz a Didática a um conjunto de procedimentos metodológicos. Esta postura sugere a supressão da Didática geral em favor das Didáticas específicas vinculadas às disciplinas escolares. Esta tendência foi discutida por Candau (1988).

Os teóricos da educação que propugnam uma relação harmônica entre o ensino e a aprendizagem estão, na verdade, promovendo a cisão de ambos. Esta cisão resulta de uma compreensão estritamente epistemológica tanto do ensino quanto da aprendizagem. Em outras palavras, ao privilegiar o conhecimento e a aprendizagem, os professores brasileiros suprimem o Ser e o ensino. Assim, o primeiro é reduzido ao sujeito cognoscente e, por consequência, o segundo torna-se um instrumento da aprendizagem ou um meio para que ela ocorra.

Numa abordagem ontológica, fundada na Ontologia do Ser Social, o que se estabelece entre o ensino e a aprendizagem é uma tensão dialética. Nela, um termo não subjuga nem suprime o outro, contudo, nunca há nem jamais haverá harmonia entre eles. Esses termos são opostos e distintos entre si e, ao mesmo tempo, se completam, constituindo assim uma totalidade: essa é a chave do movimento dialético. Dessa forma, o ensino e a aprendizagem são opostos, mas não se excluem, ao contrário, se completam. Por outro lado, o ensino e a aprendizagem não são harmônicos porque a relação entre eles não é imediata: ela é mediada tanto pelo professor quanto pelo aluno.

\section{Considerações finais}

Neste texto a mediação é compreendida na perspectiva da Ontologia do Ser Social, que foi desenvolvida por K. Marx a partir dos fundamentos da razão dialética formulados por G.W.F. Hegel. Nele mostra-se, por meio da particularidade que é a 
relação entre o geral e o singular, a presença da mediação tanto na relação ensino aprendizagem quanto no vínculo que se estabelece entre o professor e o aluno.

Também com base na mediação, apresenta-se o ensino como objeto da Didática e sustenta-se que nele reside a especificidade dela. Além disso, indica-se o caráter precursor da Didática, assinalando-se que tal caráter decorre do seu objeto.

Ao compreender a Didática com base na mediação e na Ontologia do Ser Social, pode-se superar o caráter prescritivo que a ela, geralmente, se atribui. A Didática pode ser, e tem sido, quase sempre prescritiva, mas esta não é a sua única possibilidade nem a mais indicada, principalmente, quando se afirma a intenção de formar 'alunos críticos' ou, mais ainda, 'cidadãos críticos'. Se uma das características do 'aluno crítico' for, por exemplo, a capacidade de examinar a realidade a partir do estabelecimento de relações entre os processos que fazem parte dela, a Didática não pode limitar-se a prescrever, deve, ao contrário, preocupar-se em mostrar como se estabelecem as relações entre esses elementos, aparentemente isolados. Assim, a Didática pode contribuir para a formação do ser social que é, necessariamente, crítico.

\section{Referências}

CANDAU, Vera. Maria. Rumo a uma nova Didática. Petrópolis: Vozes, 1988.

GARAUDY, Roger. Para conhecer o pensamento de Hegel. Tradução de Suely Bastos. Porto Alegre: L\&PM, 1983.

LUKÁCS, György. Ontologia do Ser Social: a falsa e a verdadeira ontologia de Hegel. Tradução de Carlos Nelson Coutinho. São Paulo: Livraria Editora Ciências Humanas, 1979a.

LUKÁCS, György. Ontologia do Ser Social: os princípios ontológicos fundamentais de Marx. Tradução de Carlos Nelson Coutinho. São Paulo: Livraria Editora Ciências Humanas, 1979b.

LUKÁCS, György. La categoría de la particularidad. In: Estética I. Tradução de Manuel Sacristán. Espanha: Grijalbo, 1982.

MÉSZÁROS, István. Marx: a teoria da alienação. Tradução de Waltensir Dutra. Rio de Janeiro: Zahar, 1981.

WARDE, Mirian Jorge. O Estatuto epistemológico da Didática. In: Ideias, nº 11, p 48 55, 1991. 


\section{Como referenciar este artigo}

ALMEIDA, José Luís Vieira de. Os fundamentos ontológicos da didática: a mediação compreendida a partir da ontologia do ser social. Revista on line de Política e Gestão Educacional, Araraquara, v.20, n.3, p. 514-527, 2016. Disponível em: <http://dx.doi.org/10.22633/rpge.v20.n3.9757>. ISSN: 1519-9029.

Submetido em: agosto/2016

Aprovado em: outubro/2016 